\title{
OPPOSITION POLITICS AND THE CHALLENGES OF FRAGMENTATION IN BOTSWANA
}

\author{
Onalenna Doo Selolwane and Victor Shale
}

\author{
Dr Selolwane is a senior lecturer in the Sociology Department \\ at the University of Botswana \\ P/Bag 0022 Gaborone, Botswana \\ Tel: +267 355 2758; Fax: +267355355 4196 \\ e-mail: selolwane@mopipi.ub.bw
}

Victor Shale is a researcher at EISA and a doctoral candidate in the Political Science Department at the University of South Africa

P O Box 740 Auckland Park 2006

Tel. +27011 4825495 Fax +27086 6046528

e-mail: victor@eisa.org.za

\begin{abstract}
It has become an article of faith that in modern political life political parties are the legitimate and logical instruments through which the diverse interests of groups within any societal polity should be mobilised to negotiate peaceful coexistence and democratic governance. The failure of these instruments to perform this role in that manner in societies outside the Anglo-Saxon cultures in which they were born is too often glossed over as a reflection of certain persisting innate inabilities on the part of the non-Anglo-Saxon people on which they were imposed. However, it is the contention of this paper that it is not always very helpful to study political institutions born in one culture and grafted onto another by simple reference to their characteristics in the culture of their birth. Rather, it is more useful to acknowledge the historical specificity of their transfer and examine how this has inter-phased with the new cultural milieu to redefine their characteristics and define future directions for change. This paper is a study of Botswana's political parties and their relations. Specifically it seeks to examine inter-party relations to assess prospects for opposition party cooperation for effective competition for the governing mandate.
\end{abstract}




\section{INTRODUCTION}

Botswana's post-independence history has been characterised by rapid economic growth and matching social change where a critical urban population has emerged to mobilise sectional interests and compete to influence government policy. This has led to major shifts away from traditional structures of relations between the governing authorities and the governed towards more liberal dispensations where the governed have increasingly come to make demands on the state.

In this changing political atmosphere some citizens have begun to put pressure on political institutions as well as the state to create more effective representation and more equitable processes of distribution of power.

The media have provided a voice for the public demand that these institutions reconstitute themselves into meaningful organs for competitive politics. The opposition parties have borne the brunt of public criticism for their penchant for fragmenting the growing opposition vote through persistent splits. Pressure is also mounting on the ruling party for electoral reforms that would better reflect increasing disenchantment among certain sections of the populace with its governance performance. The source of this public concern is that elections in Botswana since 1965 have been dominated by the Botswana Democratic Party (BDP).

This fact has attracted considerable criticism even though Botswana has also been inundated with accolades for being the most stable in the Southern African Development Community (SADC) region and on the continent at large (Molomo 2004; Somolekae 2005). Many observers (Matlosa 2003; Somolekae 2005; Molomo 2004) blame the lack of meaningful competition for political power on the country's constituency based first-past-the-post (FPTP) electoral model. But in fact, while FPTP has enabled the ruling party to control a greater share of the governing mandate than is reflected by the share of actual votes, the party has still had an overall electoral majority which has helped sustain its power in the context of a weak, fragmented and disjointed opposition.

Fragmentation and party splits have been a major feature of political party formations in Africa. But in Botswana those characteristics have historically been confined exclusively to opposition parties. As a result, it is the opposition body politic that has had to deal with the challenges of party unity while the ruling party has enjoyed the monopoly of broad-based national appeal.

This paper examines how the opposition parties have dealt with the challenge of fragmentation and their response to mounting public pressure for better political representation. 


\section{A HISTORY OF OPPOSITION UNITY TALKS: FOUR DECADES OF FAILURE}

As already noted, in Botswana fragmentation has been the exclusive preserve of oppositional politics for four decades. That fragmentation has historically been accompanied by reconciliation efforts in an attempt to build a viable multiparty political system. The Bechuanaland People's Party (later Botswana People's Party - BPP) took the trail-blazing lead as both the country's first national party and the first party to break up into splinter groups before the first general election in 1965. It was formed in 1960 under the leadership of Kgalemang Motsete (president), Philip Matante (vice-president) and Motsamai Mpho (secretary general) with the agenda of agitating for self rule by 1963 and full independence thereafter. This desire for independence was publicly expressed at the party's first conference in December 1961 as well as by Phillip Matante on behalf of the party at the United Nations in 1962. However, before the end of 1962 the party had splintered. Some observers have put this down to personality differences between the party's leaders but party insiders suggest it also had roots in ideologically motivated rifts in South Africa's African National Congress (of which some key members of the BPP also had longer standing membership) and in differences over the management of funds donated to the party for institution building.

Whatever the reasons, the split, and the ensuing public confrontations and fights not only diminished the organisational strength of the party and its capacity to mobilise support, they also undermined its credibility as a new institution for processing public interest and political power. For while the BPP was undergoing this self-destruction a new rival, the Botswana Democratic Party (BDP), was emerging to mobilise an alternative nationalist voice for independence. With such a rival, fragmentation was appreciated as a problem by the BPP factions from the earliest stages. According to one former member of the BPP executive committee, Klass Motshidisi, the first person to motivate reconciliation of the splinter groups was Kenneth Koma on his return from studying abroad. ${ }^{1}$ In these earliest attempts at party reconciliation discussions about possible unity centred on two possibilities which are instructive because of the frequency with which they would feature in future attempts at reconciliation.

Interview, 11 February 2006, at the Motshidisi residence, Palapye. Kumbulani Williams, national treasurer of the Botswana People's Party, in an interview on 7 February 2006 at the Gaborone Sun Hotel, Gaborone, also acknowledged Koma's initiative. 
These options were a) a merger of the splinters or b) an electoral pact not to compete against one another. The electoral pact would work under the auspices of an umbrella body (the Botswana United Front) to which all the splinter parties would be affiliated. After the talks had failed and the splinter groups had gone to the 1965 elections divided, Koma reconvened fresh talks to negotiate between pact and merger options. When this round of talks also failed some decided to abandon their factions and regroup to form the Botswana National Front (BNF) in 1966: thus ironically concretising a party splinter into a fully fledged new party.

This pattern of party split, followed by unity talks, followed by new party formations out of factions has been a recurring theme in opposition politics ever since (for instance, in 1969, 1974, 1991, 1999, and 2002). The BNF alone has spawned some six splinter parties since its own formation. Until the mid-1990s, however, the BNF, judging by both the increasing number of electoral constituencies in which it was able to field candidates and the share of votes it garnered, was the only opposition party to make net gains out of the splits and regroupings. With such obvious increases in popularity, it has also been the most reluctant of the unity negotiation partners to consider the option of single-party formation as a practical solution to the problem of split votes. The smaller partners, on the other hand, have been much more prepared to consider dissolution and regrouping into a single party.

Thus, throughout recurring unity talks over four decades, the themes and terms of negotiation have not varied significantly from the 1964 precursor. The most significant of the subsequent talks were those in 1991 when, again at the initiative of the BNF, four opposition parties (later reduced to three) began negotiations over how they could collaborate and reduce competition among themselves. In an echo of the 1960s, the stated objectives of this new round of negotiations were:

- to mobilise and unite all the people of Botswana against the ruling BDP;

- to embark on a common programme of action and coordinate activities through various joint structures;

- to form one national organisation to which all the participating parties would affiliate and contest jointly during elections to ensure there was no division, and to form a government of national unity if they won the election.

The negotiating partners (BNF, BPP and Botswana Progressive Union) considered two main options which were also reminiscent of the 1960s. These were the dissolution of the existing parties and their replacement by a new party or the 
retention of existing party identities and the creation instead of an umbrella body (the People's Progressive Front) to which the partners would affiliate. The second option, favoured mainly by the BNF, was adopted and the agreement was named the Unity Charter. The partners committed themselves to developing a common manifesto to harmonise the common policies of the parties and to drafting a constitution that would give the umbrella body a legal identity and framework. As with previous attempts the talks eventually faltered and failed before the defining principle could be tested in the 1994 election. This was also, ironically, the election which saw the BNF make history in terms of the level of electoral support (almost $45 \%$ ) and the number of parliamentary seats it secured (33\% of contested seats).

However, the BNF suffered major reversals when it underwent one of its historic splits in 1998, which saw it incurring major losses in legislative seats in the 1999 election when its splinter, the Botswana Congress Party, hived off 11 per cent of the votes and left it with just 25 per cent. In a desperate effort to reduce the damaging impact of the 1998 split, the BNF once again participated in another round of opposition unity talks initiated by a new party, the United Action Party (Bosele). With an unerringly monotonous repetition of the strategies since the 1960s which had led to spectacular failure, in this round of talks the BNF still favoured the loose alliance under an umbrella body, the Botswana Alliance Movement (BAM), while the partners seemed to push for much more solid integration.

The partners (Bosele, BNF, Independence Freedom Party, and BPP) met formally in January 1999 and by March 1999 had signed an agreement in which they committed themselves to contesting the 1999 elections with one symbol and one disc. However, in time honoured tradition, this agreement was not fully honoured and only the smaller parties went to the polls under the Alliance banner, with the leader of the main party, the BNF, claiming he had signed the agreement without fully appreciating the implications of who he was dealing with. ${ }^{2}$

Unflustered by the failure of this umpteenth round of negotiations the BNF and other smaller parties began yet another round of unity talks in preparation for the 2004 elections. The BNF went into this round of negotiations having just had yet another split, giving birth to the New Democratic Front (NDF). While

2 In an interview conducted with Matlhomola Modise (BAM Executive Secretary) and Dennis Alexander on 18 February 2006 at the Alexander homestead in Gaborone, the BAM members suggested that the BNF pulled back after signing, apparently because the BNF leader had not fully consulted his party on the details of the agreement. This was corroborated by Akanyang Magama (BNF Secretary General) in an interview on 8 February 2006 at the Gaborone Sun Hotel. In an interview with the former BNF leader himself, Kenneth Koma only acknowledged that he had signed before studying the personalities of the people he was dealing with, and that he pulled out once he understood their characters. 
this, and the circumstances of the split, put considerable pressure on the BNF's credibility as the main challenger to the ruling party, there was even more serious pressure from the threat of its erstwhile splinter, the $\mathrm{BCP}$, which had decimated its support and could also attract the partnership of the smaller parties. So the period leading to the 2004 elections arguably presented the greatest challenge to opposition unity (with two significant opposition parties poles apart) at a time when, historically, the opposition had the greatest support from the electorate.

Still smarting from the injurious and rather violent split of 1998 the BCP and BNF did not contemplate each other as potential partners even though they in fact held the key to the most meaningful opportunity for opposition unity. The results of the 2004 election, like that of 1999, would prove just how wasteful inter-opposition rivalry was when the two parties succeeded in splitting the vote once again and gaining no seats: thus giving all the advantage to the ruling BDP which, despite its overall decline in actual votes, still won the largest share of parliamentary seats.

In spite of this dismal picture there was a small but very significant victory for opposition unity when the negotiations between the BNF and other smaller partners succeeded. The former umbrella Botswana Alliance Movement had transformed itself into a fully-fledged political party (somewhat reminiscent of the formation of the Botswana National Front), and was among the key players in the fresh unity talks which started informally in 2003. This round of negotiations was notable for the fact that it was the first in a history spanning four decades of failed negotiations which actually led to a signed contract that the partners (the BPP, BNF and BAM) were able to honour right through to the polls.

\section{THE PROTOCOL OF ELECTION PACT AND THE 2004 ELECTION}

The Protocol of Election Pact was signed in Francistown on 13 September 2003 by the leaders of the BNF, the BPP and the BAM. The agreement bound the signatories to a partnership in which they would work together to avoid the opposition vote-splitting that had, in the past, enabled the ruling BDP to win elections. In determining which of the partners would contest which constituency in the coming elections, the protocol parties used performance in 1999 as a guide to their respective strengths. However, they also agreed that where the partner with the strongest previous constituency support no longer had a strong and credible candidate for that constituency they could request other pact members to select a candidate to run on the eligible partner's ticket. The partners further agreed that they might refrain from fielding a candidate against a non-pact opposition candidate if they all so agreed. 
Although it started with a rather ambitious preambular statement of intent to remove the BDP from power and offer the electorate an alternative government, the whole tenor of the Protocol of Election Pact is actually cautious and reflects much more modest goals. In fact, it is more a set of tentative first steps towards building mutual trust among the signatories than one of bold steps towards developing a government in waiting. Given the long history of failed attempts involving, particularly, the two oldest parties in the partnership, the BNF and the $\mathrm{BPP}$, and the obvious fact of a missing key player in opposition negotiations (the $\mathrm{BCP})$, there was merit in modesty and pragmatism. The protocol was clearly aimed at demonstrating to partners and observers alike that the opposition had matured to the point where the parties could carry negotiations to a successful conclusion without reneging on commitments to the process and the final agreements.

Because the agreement was carried through to the election it has offered, for the first time in opposition history, an opportunity to assess the merits and practicalities of opposition cooperation in terms of the stated objective of reducing split votes. It is also an indicator of the credibility of the parties as possible candidates to be entrusted with the mandate to govern. Overall, the gains in terms of minimising split votes were very modest. In at least two constituencies (Francistown and Maun), the partners failed the test of non-competition against one another and avoidance of split votes, to the detriment of the protocol. And virtually none of the smaller partners delivered a constituency seat for the partners. This was perhaps to be expected, given that the negotiations started too late to afford consistent cross-party support for candidates and a major player in the game (the $\mathrm{BCP}$ ) was not part of the agreement and therefore succeeded in splitting a fair proportion of the votes.

But the merit of opposition cooperation can also be measured in terms of other, perhaps less tangible dividends. A critical one is that of credibility, which is essential for developing voter confidence in the political parties as potential candidates for state power. This is particularly true of Botswana's opposition parties as they have never been tested in the practical challenges of governing a country. On the contrary, the opposition has built a reputation for injurious conflicts and fragmentation and an apparent readiness to walk away from problems instead of solving them. Such behaviour does not accord with candidature for running the affairs of the state where the option to walk away is not on the cards. The successful management of the protocol commitments provided the first step towards undoing the self-inflicted damage that was carried out over an extended period.

As a test of credibility, the successful conclusion of the protocol was particularly significant because the partners were up against a rival party with a 
track record of performance that was better than those of many of its peers in Africa in terms of the management both of state affairs and of its own internal affairs. The credibility of the opposition thus had to be earned rather than accidentally acquired as a windfall from the bad governance practices of the ruling party. By upholding the commitments of the protocol up to the elections and beyond, the pact members demonstrated to a sceptical voting public that they had made a break with the legacy of reneging on processes and agreements. This was a small beginning, requiring continuous reinforcement for electoral pay-off. But its significance cannot be overstated.

At a more practical level the protocol tested the viability and efficiency of the strategy adopted for formulating how to distribute electoral constituencies among the partners. Given the limited time in which the parties had to negotiate, and the exploratory nature of the cooperation, the idea of using the 1999 election as a gauge of electoral performance was probably the most pragmatic option. Nonetheless, it was a strategy that assumed that four years after the most recent elections the structure of party support would not have altered significantly. The weakness of this assumption was probably demonstrated by the failure to wrest any seats from the BDP, and the loss of some that had been in opposition hands. Basically the smaller partners lost all the seats entrusted to them.

The 2004 election saw the BDP obtaining the majority of 11 out of the 14 districts and town councils. It has the overwhelming majority in the Central District Council, where it has 127 seats against 11 for the opposition parties (BAM, $\mathrm{BCP}$ and $\mathrm{BNF}$ ) combined. In the few councils where the opposition holds the majority, such as the BNF in the Gaborone City Council, there is little difference in numbers between the BNF and the BDP (see Table 1). While the BDP was once mainly dominant in the rural areas its support has now transcended rural boundaries, as is evident in the case of the allocation of seats in the Gaborone City Council. The figures suggest that opposition parties still have a great deal of work to do to make an impression at local government level before they can hope to pose a serious challenge to the BDP at constituency level.

As shown in Table 1 the BNF is the only protocol signatory to have won 12 constituency seats, despite having lost the very important Selebi Phikwe West seat contested by its leader. The other signatories performed poorly despite the fact that they had placed their candidates in constituencies where they believed they had strong support. They were defeated by the BCP, whose votes exceeded those of all the protocol partners (BPP and BAM) combined. A further example of the weakness of the 2004 election strategy was that instead of allowing the membership of the partners to indicate their preferred candidate through, for instance, joint primary elections, the candidates were often imposed on the voting 
Table 1

Distribution of Votes and Parliamentary Seats Since the 1965 Elections

\begin{tabular}{|l|r|r|r|r|r|r|r|r|r|}
\hline \multicolumn{7}{|c|}{ Distribution of seats \% } \\
\hline Party & 1965 & 1969 & 1974 & 1979 & 1984 & 1989 & 1994 & 1999 & 2004 \\
\hline BDP & 90 & 77 & 84 & 91 & 82 & 91 & 68 & 83 & 77 \\
\hline BNF & & 10 & 6 & 6 & 15 & 9 & 33 & 15 & 21 \\
\hline BCP & - & - & - & - & - & - & - & 2 & 2 \\
\hline BPP & 10 & 10 & 6 & 3 & 3 & 0 & 0 & 0 & 0 \\
\hline BAM & - & - & - & - & - & - & 0 & 0 & 0 \\
\hline Other & 0 & 3 & 4 & 0 & 0 & 0 & 0 & 0 & 0 \\
\hline TOTAL $\%$ & 100 & 100 & 100 & 100 & 100 & 100 & 100 & 100 & 100 \\
\hline Total & 31 & 31 & 32 & 32 & 34 & 34 & 40 & 40 & 57 \\
No of Seats & & & & & & & & & \\
\hline & & & & & & & & & \\
& & & & & & & & & \\
\end{tabular}

Source: Botswana Independent Electoral Commission Election Reports 
members, who displayed their displeasure by withholding their support. ${ }^{3}$ This issue has therefore raised the fundamental question of who should be the final arbiter of the candidates representing the partners: the party leadership or the supporters? It is a question that is not lost on the partners and will demand the attention of negotiators and challenge both their negotiations skills and the parameters of opposition cooperation. As a lesson in pragmatism it has certainly afforded the protocol members an opportunity for deeper reflection on the complexities of cooperation.

Unlike any of the previous negotiation processes the protocol had a provision for a review of the agreement and related practices immediately after the 2004 election, and with a view to using the post-mortem results to inform amendments to the contract. This is also a significant breakthrough because, generally, the opposition had never systematically reviewed its past attempts so it could learn from its mistakes. And even in the process of gathering data for this report it was obvious that members were giving personal opinions about why their previous negotiations had failed rather than reflecting on the outcome of a collective review.

The lessons of the protocol are not restricted to the activities of participating partners or the contents of their agreement. Rather they can also be read from the non-participation, particularly of the BCP. Firstly, the absence of the BCP probably ensured a reduction in tensions that might have derailed the negotiations given both the relative negotiating strength of the party and the outstanding grievances that had not been discussed since the break up with the BNF. Secondly, the absence demonstrated the capacity of the party to split the opposition votes and thus help maintain the ruling party's advantage. Thirdly, it put the BCP under the public spotlight and pressure because it focused on building its own organisational capacity while ignoring the public demand to consolidate the opposition votes.

The protocol experience also opened up opportunity for non-party members of the public to intervene in intra-party reflections to highlight the dual position of political parties and remind the leaders of the responsibilities of parties both as public institutions and membership organisations. Here the importance of listening to the voices of vested interests operating outside party structures was emphasised. ${ }^{4}$ Another point to be learnt from the reluctance of the BCP to join the negotiations because of their proximity to the elections has been the critical need for these processes to be initiated with adequate time for reflection and broadbased consultation to enhance membership support and ownership.

\footnotetext{
Interviews with Matlhomola Modise (BAM), Dennis Alexander (BAM), Akanyang Magama (BNF), and Kumbulani Williams (BPP).

4 Minutes of meetings between the Committee on the Enhancement of Democracy in Botswana and representatives of opposition parties.
} 
With all these intangible but significant dividends, the protocol has underscored the merits of opposition party cooperation for the consolidation of votes.

\section{THE INTER-ELECTIONS MEMORANDUM OF UNDERSTANDING}

Drawing strength from the relative success of the Protocol of Election Pact as an example of cooperation, the opposition parties entered into an inter-election pact officially signed as a Memorandum of Understanding (MoU) on 15 August 2005. The initial signatories were the BAM, the BCP and the BNF. The BPP added its signature in 2006. In many ways the memorandum consisted of the same basic principles and terms of engagement as the earlier protocol, but was specifically limited to by-elections occurring between 2005 and 2009. For instance, it used the formula of the previous election results to determine which partner is eligible to contest the by-election in a specific constituency or ward. But where the protocol was less cautious about its lifespan, the memorandum spelt out very clearly that it was an interim measure and the contents of the agreement should not be construed as a model for future negotiations.

A major achievement of the MoU was that it brought together the two key opposition parties (the BNF and the BCP) which had the most significant electoral support and therefore the greatest capacity to inflict serious electoral injury on one another and on the collective (see Table 1). The immediate benefit of this cooperation was that with the assistance of its allies the BNF not only managed to retain the constituency seat of Gaborone West North in the October 2005 byelection but was also able to bring its leader, Otsweletse Moupo, into Parliament, where he assumed the position of Leader of the Opposition.

This victory also cleared potential conflict between the BNF leadership and the MPs in terms of the latter's subordination to the leader of the party. In most cases where the leader of the party is not in Parliament this invariably leads to serious intra-party tensions. It follows, therefore, that the absence of Moupo from Parliament and the likely tension that this would have caused in the long run could have jeopardised the critical role of the BNF in the opposition unity talks.

Like the protocol before it, the MoU was primarily a tentative step to test modest terms of engagement. It also enabled the parties to reflect without the pressure of looming general elections. The by-elections conducted under the auspices of the MoU in the first 12 months of its existence have generally been perceived by the signatories to be a success in terms of limiting split votes and enabling the parties to build rapport and trust prior to negotiations for the 2009 election. Each successful execution of this contract added considerably to the credibility of opposition cooperation and of the parties themselves. 
However, its potential to deliver on confidence-building was curtailed at the start of its second year of existence when a breakdown in the negotiation talks for the 2009 general election led to the partners abruptly reneging on the $\mathrm{MoU}$ as well. In the context of increased pressure from the electorate for political maturity it is important that the process and factors leading to the breakdown in opposition party negotiations and contracts be examined more carefully for clues to the future of democratic governance and plural politics in Botswana

\section{THE 2006 UNITY TALKS AND DILEMMAS}

\section{The Constitution, Presidential Elections and Opposition Unity Options}

To appreciate fully the dilemmas opposition parties face when they have to negotiate terms of cooperative engagement in their bid to wrest the governing mandate from the BDP we must begin by examining the legal environment that determines their range of choices. To that end, it is important to note firstly that the Constitution of Botswana does not provide for a president who is directly elected by the popular mandate. Instead, the voters elect parliamentary candidates whose popular support is automatically also a vote for the president each of these candidates would have indicated as their choice when they registered their own candidature. Secondly, at this stage in the procedures for presidential elections, unless the parliamentary candidate is standing in a constituency which is unopposed, that candidate may only choose a presidential candidate with whom he/ she shares a voting colour and symbol. The specific constitutional provision is in paragraph 32 (3) (c), which states that:

Where the Parliamentary election is contested in any constituency a poll shall be taken in that constituency at which the votes shall be given by ballot, and for the purposes of that poll any parliamentary candidate who declared support in accordance with paragraph (a) for the particular Presidential candidate shall use the same voting colour and symbol, if any, as may have been allocated under any law for the time being in force in Botswana to that Presidential candidate for the purpose of the Presidential election.

The import of this constitutional provision for opposition party negotiations for vote consolidation is that in relation to selecting a president they can, in the first instance, only practically pool their support if both their preferred presidential candidate and all their parliamentary candidates share the same voting colour and symbol because the presidential choice is tied to parliamentary elections. 
Only legally registered political parties can have voting colours and symbols, so to comply with this constitutional provision the opposition parties must decide whether they will form a brand new party, to which they will all affiliate, or affiliate to one of their partners and use that party's colour and symbol.

Because the qualification for president is that more than half of the elected members of Parliament must have nominated the presidential candidate of their choice in the run up to the general elections, in the event that the general election does not, in fact, produce a qualifying presidential candidate, the next procedure is to follow the provisions of s 35(5) of the Constitution. This section provides for the elected members of the National Assembly to elect a president by secret ballot not more than 14 days after it has been determined that no one qualified for president under the provisions of $\mathrm{s} 32$ of the Constitution. The import to opposition party cooperation of this constitutional provision is that the partners could aim collectively to win 51 per cent of the parliamentary seats so that there is no qualifying president immediately after the general election. Unlike s 32, s 35(5) does not require that members of Parliament who are eligible to vote have the same voting colour and symbol ${ }^{5}$ as their preferred presidential candidate.

\section{The 2006 Unity Negotiations in Context}

In February 2006 negotiating teams representing the BNF, the BCP, the BAM, and the BPP officially commenced negotiations over how their parties could cooperate in order to avoid split opposition votes and thereby enhance their chances of unseating the BDP in the 2009 general election. The choice of cooperative models that they brought to the negotiation table could be summed up succinctly as between a union that would give them a presidential candidate in terms of s 32(3) of the Constitution and an agreement that could give them a coalition government under the provisions of s 35(5) if they succeeded in winning enough votes collectively to invoke this provision. Each negotiating team brought to the table two alternative models ranked in terms of first and second preference. But, in all, there were just three models of cooperation to consider: an umbrella body (BCP and BAM first preferences), The alliance model (BNF first preference) and an election pact (first preference for the BPP and second for the other three).

The nomenclature of an umbrella body means, in practical terms, in the context of Botswana the formation of a new political party ${ }^{6}$ to which all cooperating

5 That is, since voting colours and symbols can only be shared by those belonging to one party, this section does not require the members to elect the president only from their party.

6 In terms of Botswana law the only grouping that can contest an election is a registered political party. Individuals may also contest elections as independent candidates. 
political parties affiliate without disbanding. It is similar to the Kenyan National Rainbow Coalition, which consists of the National Alliance of Kenya and the Liberal Democratic Party; and to South Africa's Democratic Alliance, which, when it was formed in 2000, consisted of the Democratic Party, the New National Party, and the Federal Alliance. This cooperative model would certainly meet the requirements of s 32(3) if the affiliated members won the popular mandate.

An alternative with the same capacity in terms of the requirements of s 32(3) would be a model where the cooperating parties affiliate to one of the partners. In terms of the local nomenclature, this is the model currently referred to as the affiliation model. The nearest resemblance in Africa is the model used by the African National Congress (ANC) with its alliance partners, the South African Communist Party and the Congress of South African Trade Unions (Cosatu), although Cosatu is not a political party. Despite being in the alliance under the ANC brand, the three pursue their individual interests, often differing on certain issues (Habib \& Taylor 2001; Kadima 2006).

The two models cited above, despite fancy nomenclature, are actually affiliation models which differ only in terms of whether the parties affiliate to a brand new party or to an existing one. The third option the negotiating partners considered was the election pact. This is the model used, for instance, in both the 2004 general election under the auspices of the Protocol of Election Pact and in the by-elections held since August 2005 under the dispensation of the Memorandum of Understanding. But in terms of selecting a president, this model is not in the same league as the two above (given the fragmentation of their voter support) as it can only be brought into play in the event of the general election not producing a qualifying president where the cooperating partners agree to form a coalition government if their elected members of Parliament make up 51 per cent of the eligible voters in the National Assembly.

Thus, the real choice among the negotiation teams was between an affiliation option and a loose pact. The two larger parties, the BNF and BCP, favoured an affiliation model, but differed fundamentally over whether that affiliation should be based on a new party (the BCP's umbrella body) or an old one (the BNF's affiliation version). With a track record of nine general elections that had seen it increase its share of the popular vote from a modest 14 per cent in 1969 to a peak of 37 per cent in 1994, when it suffered a set back because of a split, it was highly unlikely that the BNF would be ready to give up its brand name for a completely new identity under an umbrella body: particularly with the 2004 election indicating it had made some modest recovery after the split.

On the other hand, the BCP had narrowed the gap between it and the BNF since its maiden 1999 electoral contest and would not readily acquiesce to being swallowed back into the BNF as a mere affiliate. With the stakes so high it was 
obvious that the time for a fully united opposition challenging the BDP as one party had not yet arrived since the two key players had far more to lose by choosing one form of affiliation over the other.

The fall back was therefore the pact model, which only the BPP had identified as first choice. And since all the other parties had identified it as a second choice it offered room for a consensus and had the potential to act as a bridge while the parties worked on their differences. However, the BNF withdrew its initial support for this option and, in the same stroke, removed any possibility for consensus building. This withdrawal raises the question of just what it was that the opposition parties were negotiating about. Since the unity talks were specifically targeting the 2009 general election the issue is what were the parties aiming to achieve in 2009 through negotiated cooperation? If the target was to consolidate their electoral support for purposes of taking government office in 2009 their choice, in the context of both the legal framework and the political climate, was, practically, to form a strong alliance through affiliation to either a brand new party (ie, the $\mathrm{BCP}^{\prime} \mathrm{s}$ umbrella option) or an existing one (ie, the $\mathrm{BNF}^{\prime}$ s affiliation option).

If, on the other hand, the aim of consolidating electoral support was primarily to strengthen their parliamentary opposition and then possibly negotiate a coalition government after the election if the opportunity later arose, the election pact was the most practical option and had the added advantage of having been the first model to be honoured into the elections by the signatories. It is not clearly evident from either the intra-party consultative processes of 2005 or the actual inter-party negotiation process of 2006 that the opposition parties had, in fact, thoroughly interrogated their aims and come to the negotiating table prepared with a defined goal on which they could deliberate.

On the contrary, it would appear that the goal was not stated in these specific terms and therefore allowed room for various interpretations by the negotiating teams. The lack of specification of a goal can be read from, for instance, the BNF's first tabling of the pact model as an alternative option and subsequent withdrawal of it as a negotiable option. This suggests that the initial tabling was made without serious reflection on its implications for strategic negotiation. Similarly, those parties that tabled the pact model as their first choice could not have had the same strategic goal for 2009 as those that tabled the affiliation models of umbrella body (ie, a new party) and affiliation (ie, to an existing party) because they implied different goals and therefore required fundamentally different strategies to attain those goals.

\section{The Future After the Collapse of the 2006 Unity Talks}

When the 2006 Unity Talks ended in September the situation of opposition unity was practically where it had been in 2004 with regard to the composition of the 
partners and the working model of cooperation. In terms of composition the structure is, as it was then, one major opposition party and two smaller partners. The only change was that the BNF had switched places with the BCP and was now the outsider. Both the MoU and the new talks were supposed to have carried the success of the old Protocol of Election Pact to higher ground in terms of consolidating and enhancing opposition electoral support. Clearly, the collapse of the new talks is not an ideal response to increasing voter demand for vote consolidation.

With regard to the model, for the remaining partners the election pact is also the option still sitting on the table after the exit of the BNF. Ironically, if the three remaining partners take the principle behind the BPP's latest proposal of merger, the merger or its less radical alternative of affiliation would have to be based on the strongest of these partners (the $\mathrm{BCP}$ ) to win the endorsement of the $\mathrm{BCP}$ supporters. This would potentially boost the total support for the $\mathrm{BCP}$ from the 2004 level of 17 per cent of the vote to 22 per cent, thus considerably narrowing the gap between the BCP and the BNF.

The main advantage of the collapse of the unity talks so far in advance of the general election is that, unlike in the case of all previous attempts, Botswana's voting public and the parties themselves have time to reflect on the weaknesses of recent negotiations as well as generally on the feasibility of future cooperation. So far many of the citations of public concern for opposition cooperation are based more on anecdotal evidence popularly reflected in newspapers than on a systematic survey soliciting public opinion. It is therefore not clear the extent to which the ideal of opposition unity or cooperation is shared by most of the electorate.

Since the large majority of voters are not, in fact, officially registered members of any political party, it would be useful to assess their opinions to gauge how they would translate their desired outcomes into electoral support. This might greatly influence the context within which future inter-party negotiations, if any, are conducted. The same applies to the actual members of the political parties. There is no scientifically reliable information on how the majority of these party members perceive the importance of opposition party cooperation, or the implications of the various models for the future structure of their parties.

The situation is not particularly helped by the fact that the leaders of the opposition parties have not demonstrated any outstanding leadership qualities in guiding debate and reflecting on the strategic choices available or the goals achievable. Long before the talks officially collapsed, for instance, the leader of the BNF, Otsweletse Moupo, and other members of the executive committee of the party were already making public statements that effectively rendered the negotiating teams superfluous. For instance, when the other parties raised 
concerns about the affiliation model proposed by the BNF, the BNF leader did not interpret this as a legitimate source of concern but rather sought to appeal to the logic of numbers: arguing that it was logical that the larger party should be the one to which the smaller parties affiliated. The opportunity to put forward the suggestion that perhaps the time for affiliation was not ripe, and that negotiating partners might consider an election pact as the most practical option for now, was lost.

Another member of the executive committee of the BNF, Elmon Tafa, also chose the commencement of the inter-party negotiations to make public observations about the impotence of inter-party cooperation in enhancing opposition support. Exactly why this rather lopsided analysis had to be made in newspapers rather than discussed in intra-party consultations and inter-party negotiations was not clear. But it could be, and was, construed by some observers as an attempt by a senior member of the BNF to dissuade the general members from accepting the principle of negotiation when they had already sanctioned negotiations and, in fact, sent a negotiating team to engage with other parties.

The $\mathrm{BCP}$ also demonstrated a desire for media attention by making premature public pronouncements about points of disagreement with the BNF from very early in the negotiation process. Instead of the leadership giving a balanced report on what the various models represented in terms of viable strategy alternatives, or even enlightening the public on the restrictions imposed by the constitution on choice of affiliation model, the publicity secretary of the BCP, Dumelang Saleshando, was all too ready to suggest that if the talks collapsed the person responsible should be sought in the BNF ranks.

\section{CONCLUSION}

In 2009 Botswana will go to the polls for the tenth time since the 1965 general election. Despite an uninterrupted record of multiparty electoral competition, while the voters may be uncertain about which members of Parliament their votes will return to Parliament, and hence to the executive, they already know that the highest office in the land - an office which carries executive powers to determine the composition of the Cabinet and therefore the daily management of state affairs - already has an occupant just marking time. It is therefore a fundamental contradiction of the principle of elections that the most important office in the whole process of popular elections is already settled before voters even cast the first vote!

While this state of affairs can be blamed on the system of presidential elections provided for in the Constitution a part of it is facilitated on the one hand by a combination of ineffective opposition politics, despite increasing shares of the 
popular vote, and, on the other, the constituency-based winner-takes-all election system which creates a wide margin between the share of votes and the share of parliamentary seats that determines the presidential candidate. In this context, opposition unity is crucially important to the question of narrowing the gap between votes and seats and therefore enhancing greater representation of the increasing number of voters showing disenchantment with the ruling party.

The form of opposition unity, however, has consequences for political stability that also need debate and reflection. As observed above, a model of cooperation which ushers into Parliament a number of opposition parties that can use their collective strength to force presidential elections based on s 35(5) of the Constitution can only lead to a coalition government. The result of that, based on world wide experience, is political instability deriving from the disproportionate power of smaller partners to bargain for concessions from the bigger parties, thus potentially switching their allegiance. This is the likely result of an effective election pact if it is successful in enhancing the electoral support of all its partners.

A cooperative model which brings one decisive winner into Parliament offers far more political stability. For Botswana there are two viable alternatives within this model. One is cooperation based on the affiliation of cooperating parties to one brand-new party through which they enter Parliament (the BCP's umbrella option). The other is cooperation based on the affiliation of cooperating parties to one of their partners (the BNF's affiliation optional). While they both offer equal stability the challenge will be to win one of them endorsement as a viable model. The one gives the BNF a greater advantage as the party on which cooperation is based. The other means the creation of a new party, which will require hard selling.

So, when the opposition parties return to the negotiation table, as they will inevitably be forced to do by public pressure and the challenging political situation in Botswana, many of these issues will have to be revisited with honesty and maturity to allow for informed debate and meaningful negotiation.

- REFERENCES

Habib, A \& R Taylor. 2001. Political Alliances and Parliamentary Opposition in PostApartheid South Africa. Johannesburg: KAS Seminar Report No 2.

IEC Botswana. 2004. Elections Report. On line: Available at www.gov.bw/ elections04/iecreport.pdf

Kadima, D (ed). 2006. The Politics of Party Coalitions in Africa. Johannesburg: EISA/ KAS.

Matlosa, K. 2003. Electoral system reform, democracy and stability in the SADC Region: A comparative analysis. EISA Research Report No 1. 
Molomo, M \& G Somolekae. 2002. 'Sustainable Electoral Democracy in Botswana'. Paper presented at the International IDEA Conference, Towards Sustainable Democratic Institutions in Southern Africa, Gaborone, Botswana, 8-10 May. Molutsi, P. 1991. 'Political Parties and Democracy in Botswana'. In M G Molomo \& B T Mokopakgosi (eds). Multi-party Democracy in Botswana. Harare: Sapes Trust.

. 1997. 'Elections and Electoral Experience in Botswana'. In W Edge \& M Lekorwe (eds). 1998. Botswana: Politics and Society. Pretoria: J L van Schaik. Parson, J. 1991. 'The Peasantariat, Politics and Democracy in Botswana'. In R Cohen \& H Goulbourne (eds). Democracy and Socialism in Africa. Boulder, Col: Westview Press.

Schrire, R. 2001 The Realities of Opposition in South Africa: Legitimacy, Strategies and Consequences. Johannesburg: KAS Seminar Report No 21.

Shale, V. 2006. Opposition parties' alliances and the next elections in Botswana, Lesotho and Zambia. Unpublished.

Somolekae, G. 2005. Political Parties in Botswana. EISA Research Report No 27. 